Canadian Studies in Population, Vol. 33.2, 2006, pp. 271-299

\title{
Association of Social Class with Malaria Prevalence among Household Heads in Ghana
}

\author{
Kwame Boadu \\ Frank Trovato \\ Department of Sociology \\ University of Alberta \\ Edmonton, Alberta, Canada
}

\begin{abstract}
This is an exploratory study that investigates the association of social class with malaria prevalence among household heads in Ghana. Data utilized is taken from the 1997 Core Welfare Indicators Questionnaire (CWIQ) survey of Ghana. The survey collected information on households covering a variety of topics including education, health, employment, household assets, household amenities, poverty predictors, and child anthropometry. A total of 14,514 households were interviewed, comprising 63 percent rural household heads and 37 percent urban household heads. The research method employed in this study involves the construction of a composite index of social class from six indicators namely, education, dwelling ownership, heads of cattle, modern household items, main source of cooking fuel and type of toilet facility. Logistic regression was applied in examining the association between social class and the dependent variable, prevalence of malaria. Marital status and personal hygiene were examined together with social class as the predictor variables, while sex, age, place of residence and ecological zone were introduced as control variables. The study revealed that there was no direct association between social class and the prevalence of malaria among household heads in Ghana; rather, marital status served as a mediating factor.
\end{abstract}

Key Words: Ghana, households, malaria, social class, morbidity 
Kwami Boadu and Frank Trovato

\section{Résumé}

Ceci est une étude exploratoire qui examine la corrélation entre la classe sociale et la prédominance de la malaria parmi les foyers au Ghana. La collecte des données a été puisée d'un questionnaire concernant le noyau indicateur d'assistance sociale au Ghana en 1997(CWIQ). L'information compilée sur les foyers couvrent plusieurs domaines :l'éducation, la santé, l'emploi, le gain capital par foyer, les appareils ménagers, les indicateurs de pauvreté et l'anthropométrie enfantine. Un total de 14514 foyers ont été interviewés comportant $63 \%$ des familles rurales et $37 \%$ des familles urbaines. La méthode de recherche employée lors de cette étude, implique l'élaboration d'un répertoire de classes sociales à partir de six indicateurs déterminés dont l'éducation, la propriété de demeure, le nombre de bétails, les appareils ménagers modernes, source d'énergie principale pour la cuisson et le type de toilette. La régression logistique a été appliquée en examinant l'influence de la classe sociale sur la variable dépendante, soit la prédominance de la malaria. L'état civil et l'hygiène ont été examinés ainsi que la classe sociale comme variable de commande. L'étude a indiquée que la classe sociale n'a aucune influence directe sur la prédominance de la malaria parmi les foyers mais que son influence est atténuée selon l'état civil des individus.

Mot-clés : Ghana, households, malaria, social class, morbidity

\section{Introduction and Objective}

Social class is a powerful determinant of a multitude of factors that affect the prevalence of diseases: access to resources, such as medical care and adequate housing; the nature of the physical environment; and individual resources, such as income and education that lead to differential opportunities. For example, large gradients in life expectancy by income level, educational attainment, social class, ethnic background, place of residence, etc have been repeatedly discovered in populations during the twentieth century. The association between lower social class status and adverse physical and mental health has been reported in the United States (Hollingshead and Redlich, 1958; Dohrenwend and Dohrenwend, 1969; Haan et al., 1987; Williams, 1990; King and Williams, 1992), in Great Britain (Marmot et al., 1991, 1987, Marmot and Theorell, 1988; Car-Hill, 1989) and in Scandinavia (Vagero, 1991). Higher socioeconomic status is consistently associated with longer life (Feinstein, 1993; Wilkinson, 1996). 
The association between health and socioeconomic factors has been extensively investigated in Western industrialized societies. In developing countries however, the investigation of socioeconomic inequity and disease epidemiology that has received the most attention relates to malaria. In fact, Heggenhougen et al (2003) confirm that socioeconomic factors are clearly related to the risk for malaria. The primary objective of this study therefore, is to investigate the association between social class and the prevalence of malaria among household heads in Ghana.

Towards this end, the paper would attempt a sub-grouping of the population sample into social classes on the basis of a selected number of socioeconomic factors that are deemed to be relevant and culture-specific to Ghanaian society. The identified social groups, together with other variables would then be analyzed with reference to malaria in an effort to establish a relationship, if any, between social class and malaria transmission among household heads in Ghana. The outcome, it is hoped, would provide further insights of a critical but underresearched issue regarding the social and economic aspects of malaria transmission in Africa and other developing countries.

\section{Social Class and Malaria in Africa}

Malaria is governed by a large number of environmental factors, which affect its distribution, seasonality and transmission intensity (Snow et al, 1999). Although there is a great diversity of anopheles species in Africa, members of the Anopheles gambiae complex are the principal vectors of malaria throughout most of the continent. Most malaria epidemics in Africa are due to Plasmodium falciparum, the most lethal and dominant species found on the continent. There are at least 300 million acute cases of malaria each year globally, resulting in more than a million deaths. The vast majority of malaria cases ( 90 per cent) are in sub-Saharan Africa, where malaria constitutes 10 per cent of the total disease burden. Children under five and pregnant women are most at risk (Roll Back Malaria [RBM]/World Health Organization [WHO], 2000).

Morbidity data for Ghana for the most recent decade between 1989 and 1998 attest to above. Table 1 shows that for the general population, infectious and parasitic diseases still remain the major killer, with malaria dominating the top fifteen causes of out-patient consultation for the entire period, accounting for an average of 41 per cent for all cases. Upper respiratory infections and diarrhoeal diseases are second and third respectively, from 1989 to 1994, except in 1991 with each accounting for less than 10 per cent of all cases. From 1995 to 1998 , diseases of the skin displaced diarrhoeal diseases as the third highest cause of out-patient consultation in Ghana. 
Kwame Boadu and Frank Trovato

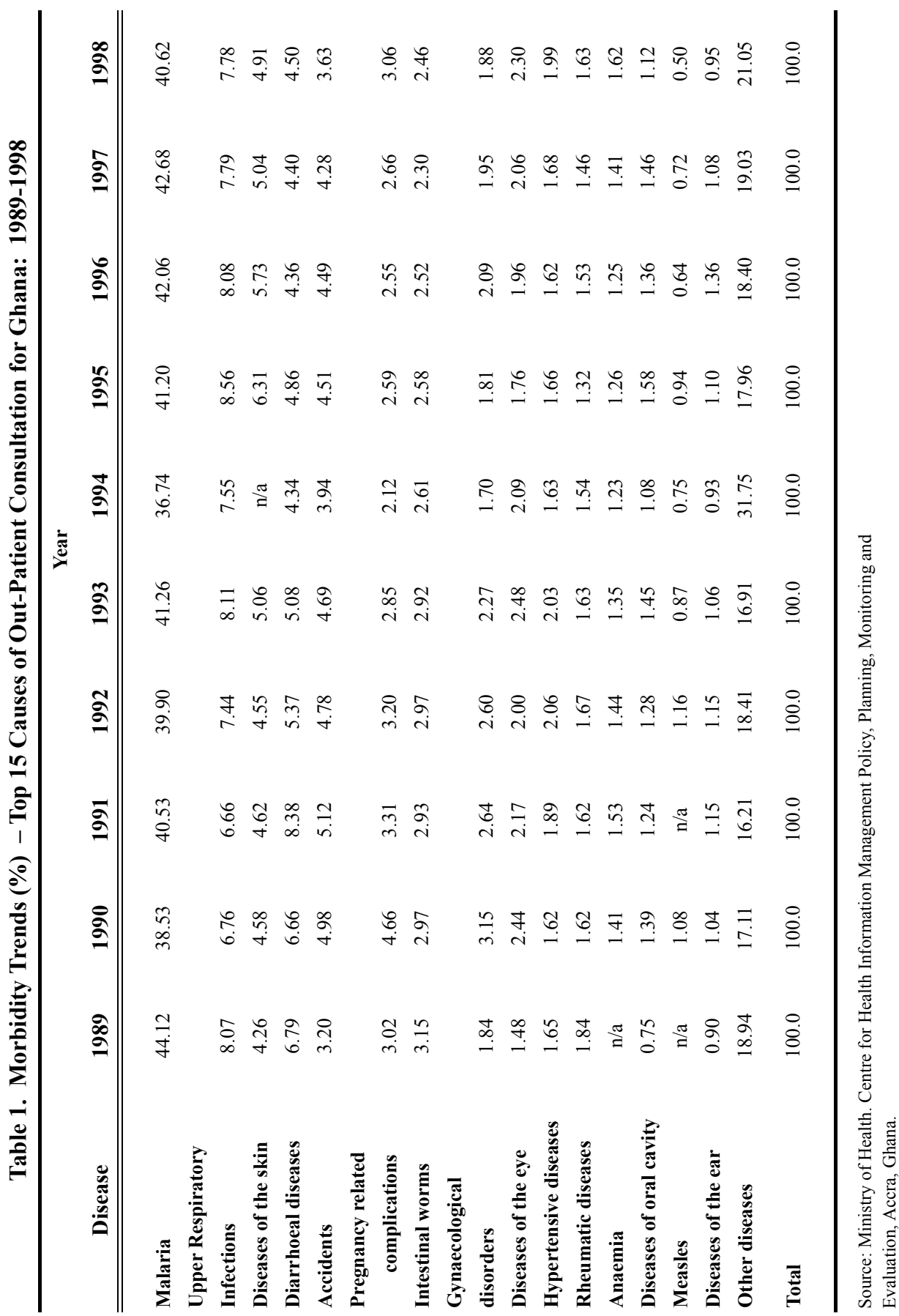
274 
Malaria is understood to be both a disease of poverty and a cause of poverty in most African countries. Poor people are at increased risk both of becoming infected and of becoming infected more frequently. Heggenhougen et al (2003) note that in malarious regions, it is the poor and underprivileged that are most at risk and experience the most mortality because of precarious living conditions and often health services. Alnwick (2000) also observes that malaria afflicts primarily the poor, who tend to live in dwellings that offer little or no protection against mosquitoes. Furthermore, Brown (1997:122) notes that "the continuation of brutal poverty and hunger in much of the world is undoutbtedly linked to large numbers of unnecessary deaths from malaria."

Child mortality rates are known to be higher in poorer households and malaria is responsible for a substantial proportion of these deaths. In a demographic surveillance system in rural areas of the United Republic of Tanzania, under-5 mortality following acute fever (much of which would be expected to be due to malaria) was 39 per cent higher in the poorest socioeconomic group than in the richest (Mwageni, 2002). A survey in Zambia also found a substantially higher prevalence of malaria infection among the poorest population groups (Roll Back Malaria [RBM] National Secretariat, 2001).

Even the severity and burden of the disease weighs disproportionately against the poor. Malaria infection during pregnancy is a major public health problem. In most endemic areas of Africa, pregnant women are the main adult risk group for malaria. The symptoms and complications of malaria during pregnancy differ with the intensity of malaria transmission and thus with the level of immunity acquired by the pregnant woman (Roll Back Malaria [RBM], 2004). Since malaria transmission intensity may vary within the same country from areas of relatively stable transmission to areas of unstable or epidemic transmission, the clinical picture of malaria infection during pregnancy may likewise range from asymptomatic to severe, life-threatening illness. In areas of Africa with stable malaria transmission, P. falciparum infection during pregnancy is estimated to cause an estimated 75,000 to 200,000 infant deaths each year (Steketee et al, 2001). A striking determinant of attendance at antenatal clinics is household wealth. According to a recent study, poor women are less likely to use antenatal services than are women from the richest households. In seven African countries south of the Sahara for which recent data are available, the percentage of rich women attending antenatal clinics was at least twice that of poor women (UNICEF/WHO, 2003).

In Ghana, both direct and indirect costs associated with a malaria episode represent a substantial burden on poorer households. A study found that while the cost of malaria care was just 1 per cent of the income of the rich, it was 34 percent of the income of poor households (Akazili, 2002). Similarly, Kuate 
Kwami Boadu and Frank Trovato

(1997) analyzed five indicators, including education, women's labour force participation, marital status, prevalence of polygamy, and ethnic affiliation using a community-based, prospectively collected data set and found that the burden of illness rests disproportionately on the economically disadvantaged women who were not employed, women living in poor neighbourhoods, and those living in households without modern amenities.

Trials of insecticide-treated nets (ITNs) in the 1980s and 1990s showed that ITNs reduced deaths in young children by an average of 20 per cent. Before the development of ITNs as a new technology in the mid-1980s, people in many countries were already using nets, mainly to protect themselves against biting insects and for cultural reasons (Robert and Camevale, 1991; Aikins et al., 1994). It was only recently appreciated that a net treated with insecticide offers much greater protection against malaria. Unfortunately, the commercial price of nets and insecticide is beyond the poorest income groups of the population (World Health Organization, 2003). Ziba et al (1994) found that in Malawi, use of malaria prevention measures (bednets, insecticides, mosquito coils, other insect repellants, burning leaves, etc) was income-dependent. In households where the head earned a larger than average income, use of commercial methods (mosquito coils, insecticide spray, bednets) was more common. Use of inexpensive, and less effective, natural methods (burning leaves, dung, or wood) was associated with lower income.

\section{Hypothesis}

In light of the foregoing, social class is considered a key factor in malaria transmission. Therefore, as indicated earlier, the hypothesis examined in the study posits that malaria prevalence among household heads in Ghana is a function of social class. It is predicted that the prevalence of malaria among the upper class would be lower than among the lower class. This hypothesis is tested for rural and urban populations. This differentiation is necessary and important because the underlying dimensions of social stratification in Ghana are not the same for rural and urban populations.

\section{Data}

The study utilizes data from the 1997 Core Welfare Indicators Questionnaire (CWIQ) survey conducted by the Ghana Statistical Service in collaboration with the World Bank. The survey was designed to provide simple and reliable statistical indicators for monitoring poverty and the effects of various development policies, programs and projects on living standards in Ghana. The 
survey was based on a two-stage, stratified, nationally representative sample of households. The National Sampling Frame of Enumeration Areas (EAs) with population and household information formed the basis of the sample design for the survey. The frame was first stratified into three ecological zones, namely coastal, forest and savannah, and then into rural and urban EAs. Information solicited from households were on the following modules: background characteristics of household members; education; health; employment; household assets; household amenities; poverty predictors; and child anthropometry. In all, 14,514 households

were successfully interviewed. The average household size was 4.1, with rural households having an average household size of 4.3 compared with 3.8 for urban households. Only household heads were selected for this study, with rural household heads constituting 63 per cent and urban household heads, 37 per cent. Males formed 68.2 per cent and 61.4 per cent of the rural and urban populations respectively, while the proportion of females was 31.8 per cent for rural and 38.6 per cent for urban. These proportions are not inconsistent with the social structure of Ghanaian society which ensures that household heads are predominantly male.

\section{Methodology}

\section{Selection of Indicators of Social Class}

Six variables were selected for the index construction in this study: highest grade of education completed; main source of cooking fuel; type of toilet facility; modern household items; dwelling ownership; and heads of cattle owned. These variables were selected on the strength of the fact that their underlying clusters or dimensions subsume a larger number of inter-correlated variables of social class in Ghana. Arguably, one such indicator is education which inherently can determine several other variables, amongst them, occupation. Occupation can be regarded as among the most useful variables to be included in the construction of an index of social class. Some authors (e.g., Centers, 1950; Mayer, 1955) suggest it is the best single index to be employed in large-scale statistical inquiries. This notwithstanding, occupational categorizations without additional information are not very useful both with respect to the number of groups they distinguish as well as the criteria on which they were based; the reason why occupation as measured in the original survey was not selected for this study. In fact, Wrong (1980) proposed a combination of occupation and income as a better objective measure of class status rather than occupation alone. Unfortunately, there was no income variable in the data set either. 
"Dwelling ownership" was chosen because it subsumes two other dwelling-type variables (i.e., 'material of walls of house' and 'number of separate rooms') and, perhaps, even land ownership in Ghana. The choice of heads of cattle was based purely on substantive reasoning because it is without question one important item of wealth and prestige in Ghana, most especially in the rural area. The exclusion of land was based on the simple reason that between land and cattle, the latter is more commonly owned. Also, modern household items, main source of cooking fuel, and type of toilet facility are perceived more as symbols of prestige and class status in the context of Ghanaian society than mere basic necessities as in Western societies hence their inclusion.

\section{Obtaining the Composite Index Scores of Social Class}

Principal Component Analysis was employed in the creation of the social class index. Two components were extracted: the first extracted component produced an explained variance of 25.17 per cent and 29.93 per cent for rural and urban respectively, whilst the corresponding percentages for the second extracted component were 18.60 and 18.01. The combined factors accounted for 43.77 and 47.94 per cent respectively (see Table 2). The component analysis procedure also provided the study with a formula for obtaining the composite index scores of social class. It is quite obvious at this point that each one of the six indicators selected does not make the same contribution to the index, both in substance and space. It was therefore considered necessary to factor this into the index construction so that the magnitude of individual contributions would be accounted for. This was accomplished by using the generated factor loadings as weights, the reason being that these loadings are assumed to indicate the correlation between the hypothesized factor (social class) and the indicators. For the purpose of this study, the factor loadings appearing in the first component (unrotated) matrix of Table 3 were used because it generated the highest maximum collective variance.

The variable, "modern household items" had the highest positive factor loading in the rural population, while "main source of cooking fuel" loaded highest in the urban population. "Education" and "modern household items" registered the next highest loadings in rural and urban respectively, followed by "main source of cooking fuel" in rural and "education" in urban. "Type of toilet facility" registered the lowest positive loading in rural while in urban, it posted a moderately high negative loading. The assumed weights were then multiplied by the score obtained by a respondent on each one of the indicators, and the sum of the weighted product was taken to represent the total index score of social class. Thus, the index score was obtained by combining the raw variables with weights that were proportional to their component loadings (Kim and Mueller, 1978), 


\section{Table 2}

Principal Component Analysis of Social Class Index of Household Heads in Ghana: Total Variance Explained, Second Combination

\begin{tabular}{|c|c|c|c|c|c|c|}
\hline \multirow{2}{*}{ Component } & \multicolumn{3}{|c|}{$\begin{array}{c}\text { Rural } \\
\text { Initial Eigenvalues }\end{array}$} & \multicolumn{3}{|c|}{$\begin{array}{c}\text { Urban } \\
\text { Initial Eigenvalues }\end{array}$} \\
\hline & Total & $\begin{array}{c}\% \text { of } \\
\text { Variance }\end{array}$ & $\begin{array}{c}\text { Cum. } \\
\text { per cent }\end{array}$ & Total & $\begin{array}{c}\% \text { of } \\
\text { Variance }\end{array}$ & $\underset{\text { per cent }}{\text { Cum. }}$ \\
\hline 1. & 1.510 & 25.165 & 25.165 & 1.796 & 29.926 & 29.926 \\
\hline 2. & 1.116 & 18.602 & 43.767 & 1.081 & 18.009 & 47.935 \\
\hline 3. & .969 & 16.143 & 59.910 & .947 & 15.775 & 63.710 \\
\hline 4. & .917 & 15.279 & 75.188 & .907 & 15.116 & 78.826 \\
\hline 5. & .776 & 12.930 & 88.118 & .686 & 11.435 & 90.262 \\
\hline 6. & .713 & 11.882 & 100.000 & .584 & 9.738 & 100.000 \\
\hline
\end{tabular}

Source: Core Welfare Indicators Questionnaire (CWIQ), 1997

Table 3

Principal Component Analysis of Social Class Index of Household Heads in Ghana: Factor Loadings in Component Matrix of Second Combination

\begin{tabular}{lcccc}
\hline \multicolumn{1}{c}{ Indicators } & \multicolumn{3}{c}{ Rural } & \multicolumn{2}{c}{ Urban } \\
& \multicolumn{5}{c}{$\mathbf{1}$} & $\mathbf{2}$ & $\mathbf{1}$ & $\mathbf{2}$ \\
& & & & \\
Highest education completed & .696 & -.079 & .695 & .197 \\
Main source of cooking fuel & .665 & -.113 & .754 & .174 \\
Type of toilet facility & .179 & .644 & -.441 & .078 \\
Modern household items & .710 & -.187 & .727 & -.121 \\
Dwelling ownership & .212 & .627 & -.108 & .751 \\
Heads of cattle & -.029 & -.503 & .099 & -.654 \\
& & & & \\
\hline Source: Core Welfare Indicators Questionnaire (CWIQ) 1997 &
\end{tabular}

Source: Core Welfare Indicators Questionnaire (CWIQ), 1997 
that is, the proportion of their contribution to the index. This is expressed as follows: TISSC $=\Sigma \mathrm{R}_{\mathrm{i}} \mathrm{W}_{\mathrm{I}}$ where TISSC $=$ total index score of social class; $\mathrm{R}_{\mathrm{i}}=$ score by each indicator; and $\mathrm{W}_{\mathrm{i}}=$ weight of indicator. Respondents were then classified into social groups depending on how they placed on the index scale.

\section{Regression Analysis}

The study posits that the prevalence of malaria prevalence among household heads in Ghana is a function of social class. Control variables employed in the analysis are sex, age, place of residence and ecological zone. With respect to sex, there is a general belief that the rate of malaria infection in males and nonpregnant females is similar (Laserson et al, 1999; Brabin and Brabin, 1992), while other studies report that the prevalence rate is higher in females than males (e.g., Giha et al., 2000; Ejov et al., 1999; Bawden et al., 1995). It is also suggested that even though both males and females in areas of endemic tropical diseases suffer from discrimination due to class inequality, poverty, and deprivation, women are particularly disadvantaged and marginalized due to structural factors within society.

Studies conducted in the Caribbean and Ghana revealed a higher risk for malaria infection for women than for men, which is attributed to the gendered-division of labour that governs the higher frequency of water contact, and, as a consequence, the higher risk of malaria infection for women. In particular, the Caribbean-Ghana study showed that "men's water contact occurred in the context of economic activities such as fishing, transporting bananas for sale, and collecting sand and stones for roadmaking, while women's water contact occurred in the context of domestic tasks including collection of water for household purposes, washing clothes, supervising children's play and personal hygiene" (Vlassoff and Bonilla, 1994:42).

Evidence also suggests that the prevalence of malaria varies with age, the risk being highest in children and the elderly (Giha et al., 2000; Bawden et al., 1995; Lienhardt et al., 1990; Jones et al., 1991). Alnwick (2000) makes the same observation that malaria is a major factor in Africa's high rate of infant and maternal mortality. But Lindsay and Martens (1998) note that malaria is responsible for high morbidity and mortality among both children and adults. Generally, age influences the transmission of malaria in different ways. First, children are the most at risk because they have not yet developed immunologically. Second, with respect to adults, the gendered-division of labour mentioned earlier plays a significant role in respect of the nature of the economic activity undertaken and the extent of exposure involved. Thirdly, pregnant women, who would normally be between ages 15 and 49 have been 
identified as the most adult group at risk of malaria (Roll Back Malaria [RBM], 2004).

Lastly, it is known that malaria is governed by a large number of environmental factors, which affect its distribution, seasonality and transmission intensity, especially with respect to rural-urban residence and ecological conditions (see e.g., Koram et al, 1995; Afari, et al., 1994). Ahmed (1989) observes that the distribution of malaria in Ghana follows distinct ecological zones and climatic conditions, especially the seasonal rainfall pattern. He notes that the normally humid climate of the forest zone and the attendant heavy and double rainfall pattern, coupled with the farming practices employed create more breeding sites and favourable conditions for malaria transmission throughout the year, whereas in the coastal zone where there is low rainfall accompanied by a relatively long period of dry weather, transmission is lower. On the other hand, the northern savannah zone which has a longer period of dry climate has lower infection rates throughout the year except in the rainy season.

Given the exploratory nature of the study, we specify a number of logistic regression models in order to establish the possible association between social class and malaria prevalence and other relevant variables. Specifically, the following models for the expected probability of malaria are examined:

(1) malaria $=f($ social class + sex + age + urban/rural residence + ecological zone)

(2) malaria $=\mathrm{f}$ ( social class + marital status + personal health practices + sex + age + urban/rural residence + ecological zone)

(3) malaria $=\mathrm{f}($ social class + marital status + social class $*$ marital status + sex + age + urban/rural residence + ecological zone)

(4) malaria $=f($ social class + personal health + social class*personal health practices + sex + age + urban/rural residence + ecological zone)

Equation (1) examines the direct effect of social class on malaria, controlling for sex, age, place of residence and ecological zone, while Equation (2) looks at the impact of the two intervening variables, marital status and personal health practices on malaria prevalence. Equations (3) and (4) examine possible interaction effects between social class and marital status, and social class and personal health practices, respectively on the prevalence of malaria. 
The study also explores the interaction between marital status and social class on the one hand, and personal health practices and social class on the other, and their respective effects on malaria prevalence. For example, if marital status is designated $\mathrm{X}_{1}$ and the moderator variable (interaction term) $\mathrm{X}_{2}$, with $\mathrm{W}_{1}, \mathrm{~W}_{2}, \ldots$ $\mathrm{W}_{\mathrm{k}}$ as the other predictors in the model, these would be represented in the logistic regression equation as:

$$
\begin{aligned}
\log \left(\frac{\pi}{1-\pi}\right) & =\alpha+\sum \lambda_{k} W_{k}+\beta_{1} \mathrm{X}_{1}+\beta_{2} \mathrm{X}_{2}+\beta_{3} \mathrm{X}_{1} \mathrm{X}_{2} \\
& =\alpha+\sum \lambda_{k} W_{k}+\beta_{2} \mathrm{X}_{2}+\left(\beta_{1}+\beta_{3} \mathrm{X}_{2}\right) \mathrm{X}_{1}
\end{aligned}
$$

The partial slope of the impact of $\mathrm{X}_{1}$ on the log odds would therefore be $\beta_{1}+$ $\beta_{3} X_{2}$ implying that the impact of $X_{1}$ depends on the level of $X_{2}$ and the multiplicative impact of $X_{1}$ on the odds is correspondingly, $\exp \left(\beta_{1}+\beta_{3} X_{2}\right)$. This can also be interpreted as the odds ratio for those who are a unit apart on $\mathrm{X}_{1}$, controlling for other predictors. This odds ratio changes across levels of $\mathrm{X}_{2}$, however.

Following from above equation, the odds of being unmarried and belonging to lower class or middle class are represented by the following exponential functions using the respective coefficients from Table 4 and the assigned coding of the particular variable.

$$
\begin{aligned}
& \text { rural/lower class: } \exp (.791+.323 * 1)=3.047 \quad----------------(i) \\
& \text { rural/middle class: } \exp (.791+.495 * 0)=2.206 \text {-------------------- (ii) } \\
& \text { urban/lower class: } \exp (.372+.090 * 1)=1.587 \quad---------------- \text { (iii) } \\
& \text { urban/middle class: } \exp (.372+.030 * 0)=1.451 \text {------------------- (iv) }
\end{aligned}
$$

Similarly, the odds of not observing personal hygiene and belonging to lower or middle class are obtained using the coefficients in Table 5 and the assigned coding of the particular variable as follows:

$$
\begin{aligned}
& \text { rural/lower class: } \exp (.427+.193 * 1)=1.859------------------(v) \\
& \text { rural/middle class: } \exp (.427+.520 * 0)=1.533-------------------(v i)
\end{aligned}
$$


urban/middle class: $\exp \left(.149-.198^{*} 0\right)=0.161$------------------- (viii)

\section{Measurement of Variables}

\section{Dependent Variable}

The dependent variable fever/malaria was extracted from the general question in the survey: What sort of sickness/injury did you suffer from in the past four weeks? This is problematic since a simple "yes" response to a question that seeks to know whether the respondent suffered from fever/malaria in the past four weeks is not sufficient to define clearly whether it is the incidence (new cases) of malaria or the prevalence (existing cases) rate, and how the presence or absence of the disease was determined. As such, it would be very difficult to obtain any meaningful information from self-reported recall of suffering from fever/malaria "in the past four weeks." In addition, possible cases of fever may have been reported as malaria. This notwithstanding, the proportion of respondents who reported fever/malaria was taken as representing a measure of the prevalence of malaria for the purposes of this study. Household heads who responded as having suffered from fever/malaria were coded as " 1 " while respondents who stated otherwise were coded as " 0 ." And consistent with the study objective, emphasis is placed on malaria in the analysis and discussion.

\section{Predictor Variables}

The main predictor variable is social class, with marital status and personal health practices acting as intervening variables. Social class is comprised of three categories namely, lower, middle and upper class. Marital status is measured as a dichotomous variable comprising "not married" and "married." Since overcrowding is a risk factor in malaria transmission, it would have been ideal to look at monogamous and polygamous marriages separately in order to establish whether the large number of people usually associated with most polygamous households in Ghana would make a difference. However, a crosstab analysis revealed that there was no significant difference in malaria prevalence between the two groups to warrant such an exercise.

"Personal health practices" or personal hygiene is a combination of three hygiene-related items: use of toilet paper rolls, toothbrush/toothpaste and packaged soap. This is measured as a dichotomous variable of respondents who do not observe personal hygiene versus those who do. There is no question 
Table 4

Logistic Regression of Malaria of Household Heads in Ghana, Rural-Urban Residence for Ghana: 1997

(Test of Interaction Effect between Social Class and Marital Status)

\begin{tabular}{|c|c|c|c|c|c|c|}
\hline \multirow[b]{2}{*}{ Indicators } & \multicolumn{3}{|c|}{ Rural } & \multicolumn{3}{|c|}{ Urban } \\
\hline & B & Significance & $\operatorname{Exp}(B)$ & B & Significance & $\operatorname{Exp}(B)$ \\
\hline Male & -0.198 & 0.013 & 0.820 & -0.385 & 0.000 & 0.681 \\
\hline (Female) & - & - & & - & & - \\
\hline $15-44$ & -0.009 & 0.922 & 0.991 & 0.067 & 0.605 & 1.070 \\
\hline 45-64 & -0.110 & 0.271 & 0.896 & 0.049 & 0.723 & 1.050 \\
\hline$(65+)$ & - & - & - & - & - & - \\
\hline Savannah Zone & -0.421 & 0.001 & 0.656 & 0.333 & 0.059 & 1.395 \\
\hline Forest Zone & 0.087 & 0.223 & 1.091 & 0.299 & 0.001 & 1.348 \\
\hline (Coastal Zone) & - & - & - & - & & - \\
\hline Not married & 0.791 & 0.000 & 2.206 & 0.372 & 0.103 & 1.450 \\
\hline (Married) & - & - & - & - & & - \\
\hline Lower Class & -0.284 & 0.125 & 0.753 & 0.088 & 0.654 & 1.092 \\
\hline Middle Class & -0.458 & 0.013 & 0.632 & 0.049 & 0.813 & 1.051 \\
\hline (Upper Class) & - & - & - & - & - & - \\
\hline LCxNM & 0.323 & 0.160 & 1.382 & 0.090 & 0.722 & 1.094 \\
\hline MCxNM & 0.495 & 0.033 & 1.641 & 0.030 & 0.911 & 1.031 \\
\hline Constant & -2.070 & 0.000 & 0.126 & -2.192 & 0.000 & 0.112 \\
\hline & Model Chi-squar & 103.614 & & & 68.819 & \\
\hline & df & 10 & & & 10 & \\
\hline & Significance & 0.000 & & & 0.000 & \\
\hline
\end{tabular}


Table 5

Logistic Regression of Malaria of Household Heads in Ghana, Rural-Urban Residence for Ghana: 1997

(Test of Interaction Effect between Social Class and Personal Health Practices)

\begin{tabular}{|c|c|c|c|c|c|c|}
\hline \multirow[b]{2}{*}{ Indicators } & \multicolumn{3}{|c|}{ Rural } & \multicolumn{3}{|c|}{ Urban } \\
\hline & B & Significance & $\operatorname{Exp}(B)$ & B & Significance & $\operatorname{Exp}(B)$ \\
\hline Male & -0.407 & 0.000 & 0.666 & -0.521 & 0.000 & 0.594 \\
\hline (Female) & - & - & - & & - & - \\
\hline $15-44$ & -0.075 & 0.426 & 0.928 & 0.035 & 0.785 & 1.036 \\
\hline $45-64$ & -0.166 & 0.093 & 0.847 & 0.009 & 0.947 & 1.009 \\
\hline$(65+)$ & & - & & & - & - \\
\hline Savannah Zone & -0.440 & 0.000 & 0.644 & 0.273 & 0.125 & 1.314 \\
\hline Forest Zone & 0.077 & 0.281 & 1.080 & 0.259 & 0.004 & 1.296 \\
\hline (Coastal Zone) & - & - & - & - & - & \\
\hline No personal health & 0.427 & 0.060 & 1.533 & 0.149 & 0.516 & 1.161 \\
\hline \multicolumn{7}{|l|}{ Personal health } \\
\hline Lower Class & -0.169 & 0.186 & 0.844 & 0.055 & 0.782 & 1.057 \\
\hline Middle Class & -0.260 & 0.043 & 0.771 & 0.099 & 0.629 & 1.104 \\
\hline (Upper Class) & - & - & - & - & - & \\
\hline LCxPH* & 0.193 & 0.590 & 1.213 & 0.200 & 0.465 & 1.221 \\
\hline МCxPH** & 0.520 & 0.072 & 1.681 & -0.198 & 0.480 & 0.821 \\
\hline \multirow[t]{4}{*}{ Constant } & -1.919 & 0.000 & 0.147 & -1.972 & 0.000 & 0.139 \\
\hline & Chi-square & 74.276 & & & 62.620 & \\
\hline & df & 10 & & & 10 & \\
\hline & Significance & 0.000 & & & 0.000 & \\
\hline
\end{tabular}

$\mathrm{LC}=$ lower class; $\mathrm{NM}=$ not married; $\mathrm{MC}=$ middle class

Source: Core Welfare Indicators Questionnaire (CWIQ), 1997. 
regarding the role of personal health practices or personal hygiene in the transmission of malaria. There is no denying that the physical environment, and people's proximity and exposure to vectors or parasites, including microbiological and parasitological factors are clearly essential for transmission of infection and constitute necessary and immediate risk factors. However, human behaviour - much of which is influenced by social, cultural, economic and political factors - affects health-promoting and disease-preventing activities, in some instances increasing risk and in others reducing it (Heggenhougen et al., 2003). Inhorn and Brown (1990:89-90) report that “... human groups have often unwittingly facilitated the spread of infectious diseases through culturally coded patterns of behaviour or through changes in the crucial relationship among infectious disease agents, their human and animal hosts, and the environments in which the host-agent interaction takes place." But most importantly, personal hygiene as used in this study also serves as a good indicator of socio-economic status since the products in question may be considered luxury goods in a poor setting.

\section{Control Variables}

The control variables introduced are sex, age, place of residence and ecological zone. Sex is represented as male and female. Age is comprised of three subgroups specifically, 15-44, 45-64 and 65 years or more. These classifications are intended to test for possible sex or age-specific effects. Place of residence is analyzed as rural and urban as control for rural- or urban-specific differences, where urban is defined as a locality with at least 5,000 people (Ghana Statistical Service, 1995). The data set was partitioned into two subsets according to rural and urban prior to executing the logistic regression analysis. Ecological zone is also comprised of three sub-groupings namely, Savannah (Northern, Upper East and Upper West regions), Forest (Ashanti, Eastern and Brong-Ahafo regions) and Coastal (Greater Accra, Western, Central and Volta) regions.

The logistic regression analysis is executed using the indicator-variable coding scheme. As would be noted from above discussion, three variables are binary coded while the other three are categorical. But in using the logistic procedure, all variables are entered as a series of "dummies" with the highest coded item of a variable designated as the reference category. To be precise, "female," "married" and "observe personal hygiene" are the respective reference categories for the binary variables in the logistic equations. For the variables, age, ecological zone and social class, their respective reference categories are age 65+, coastal zone and upper class. Thus, age groups 15-44 and 45-64 would each be examined separately in relation to age-group 65 years and over. Similarly, savannah zone is examined in relation to the coastal zone, while the forest zone is also analyzed in relation to the coastal zone. Likewise, lower class 
and middle class are each analyzed separately using the upper class as the reference category.

\section{Findings}

The regression analysis was preceded by simple cross-classifications that showed that overall malaria prevalence among household heads in Ghana is higher in the urban area (12.3 per cent) than in the rural area (11.2 per cent). Even though malaria is not a common occurrence in well established, densely populated urban areas, Jamison et al (1993) note that many tropical cities are surrounded by rapidly growing slums, which are basically a high concentration of shelters in what is still primarily a rural environment. It was also observed that the proportion of female household heads with malaria is higher compared to the proportion for male household heads in both the rural and urban areas 14.5 per cent against 9.7 per cent in rural versus 16.0 per cent against 10.0 per cent in urban. As well, the classifications showed that the oldest age-group (65+) had the highest proportion (12.9 per cent) of respondents with malaria in both rural and urban areas, while the middle aged-group (45-64) had the lowest proportion (10.5 per cent) of malaria cases in the rural area. The age-groups 1544 and 45-64 registered the same proportion (12.2 per cent) of malaria cases in the urban area. Household heads in the Forest zone recorded the highest proportion of malaria cases in both rural (12.5 per cent) and urban (14.4 per cent) areas, while household heads in the Coastal zone recorded the second highest proportion (12.5 per cent) of malaria cases in the rural area, just as the Savannah zone recorded the second highest proportion (13.7 per cent) in the urban area. Household heads in the Savannah zone also registered the lowest proportion (7.1 per cent) of malaria cases in the rural area while household heads the Coastal zone registered the lowest proportion (10.8 per cent) in the urban area.

The cross classification also showed that household heads who are married have less malaria than the unmarried, but the disparity was slightly greater in the rural area than in the urban area -15.3 per cent against 9.4 per cent in the rural area and 15.5 per cent against 10.2 per cent in the urban area. The proportion of malaria cases among household heads who observed no personal hygiene in both rural and urban areas was higher than among those who practiced personal hygiene -11.3 per cent against 10.7 per cent in the rural area versus 13.2 per cent against 10.5 per cent in the urban area. Finally, it was shown that while in the rural area the highest proportion of household heads with malaria was in the upper class (12.0 per cent), by contrast, in the urban area it was the lower class (13.6 per cent) that had the highest proportion of malaria as would be expected. The middle class had the second highest proportion (11.7 per cent) of malaria 
cases in both rural and urban areas. The pattern observed in the urban area was consistent with the stated hypothesis of this study, unlike what was observed in the rural area.

The result presented in Table 6 represents the equation that examines the direct association between social class and the prevalence of malaria among household heads in Ghana. The model chi-square for the equation is 69.531 and 57.426 for rural and urban respectively. With seven degrees of freedom, both are highly significant at $\mathrm{p}<.001$. The results indicate that the odds of having malaria in the rural area are about .95 and .88 times less for the lower class and middle class respectively as they are for the upper class. The reverse is the case in the urban area where the odds of having malaria are about 1.17 times for the lower class and about 1.09 times for the middle class respectively as they are for the upper class. However, these differences are not statistically significant.

The results in Table 7 explain to what extent the prevalence of malaria is mediated by marital status and personal health practices. The study first examines whether the addition of these variables makes a significant contribution to the prediction of malaria. This is represented by the difference in model chi-squares between the first and second regression equations (rural=99.757-69.531; urban=70.352-57.426) which are 30.226 and 12.926 respectively for rural and urban. With nine degrees of freedom, the result is highly significant $(\mathrm{p}<.001)$ suggesting that at least one of the intervening terms is important. The coefficients reveal that the significance of the set of intervening variables is due primarily to the strong impact of marital status. In the rural area, being married reduces the odds of having malaria by a factor of 1.53 while in the urban area, it reduces the odds by a factor of 1.37. Stated differently, the odds of having malaria are about 1.53 times as large for the unmarried as they are for the married in the rural area. For the urban area, the corresponding odds are 1.37 times greater for the unmarried household head.

Furthermore, it is observed that the odds of having malaria in rural and urban areas respectively are 1.13 and 1.14 times as large for household heads who do not observe any personal hygiene as they are for those who do. This outcome is consistent with what would be obtained in any modern society or population anywhere in the World where normal hygienic practices are observed. As well, all of above results are consistent with the distributions obtained in the crossclassification analysis discussed earlier. But whereas marital status is statistically significant, personal hygiene is non-significant. It can therefore be inferred that between the two intervening variables, marital status is the factor that mediates the relationship between social class and malaria prevalence among household heads in Ghana. 
Table 6

Logistic Regression: Direct Effect of Social Class on Malaria of Household Heads by Rural-Urban Residence for Ghana: 1997

\begin{tabular}{|c|c|c|c|c|c|c|}
\hline \multirow[b]{2}{*}{ Indicators } & \multicolumn{3}{|c|}{ Rural } & \multicolumn{3}{|c|}{ Urban } \\
\hline & B & Significance & $\operatorname{Exp}(B)$ & B & Significance & $\operatorname{Exp}(B)$ \\
\hline Male vs Fenale & -0.400 & 0.000 & 0.671 & -0.516 & 0.000 & 0.597 \\
\hline $15-44$ & -0.081 & 0.391 & 0.922 & 0.022 & 0.863 & 1.022 \\
\hline 45-64 & -0.168 & 0.089 & 0.846 & 0.003 & 0.981 & 1.003 \\
\hline$(65+)$ & - & - & - & & - & - \\
\hline Savannah Zone & -0.436 & 0.000 & 0.647 & 0.327 & 0.063 & 1.386 \\
\hline Forest Zone & 0.078 & 0.271 & 1.081 & 0.283 & 0.001 & 1.327 \\
\hline (Coastal Zone) & - & - & - & & - & - \\
\hline Lower Class & -0.055 & 0.629 & 0.947 & 0.158 & 0.212 & 1.172 \\
\hline Middle Class & -0.127 & 0.259 & 0.881 & 0.082 & 0.535 & 1.085 \\
\hline (Upper Class) & - & - & - & & - & - \\
\hline Constant & -1.617 & 0.000 & 0.198 & -1.925 & 0.000 & 0.146 \\
\hline & Model Chi-square & 69.531 & & & 57.426 & \\
\hline & df & 7 & & & 7 & \\
\hline & Significance & 0.000 & & & 0.000 & \\
\hline
\end{tabular}

Source: Core Welfare Indicators Questionnaire (CWIQ), 1997. 
Table 7

Logistic Regression: Inclusiion of Intervening Variables to Equation in Table 4 for Ghana Household Heads

\begin{tabular}{|c|c|c|c|c|c|c|}
\hline \multirow[b]{2}{*}{ Indicators } & \multicolumn{3}{|c|}{ Rural } & \multicolumn{3}{|c|}{ Urban } \\
\hline & B & Significance & $\operatorname{Exp}(B)$ & B & Significance & $\operatorname{Exp}(B)$ \\
\hline Male & -0.204 & 0.010 & 0.815 & -0.388 & 0.000 & 0.678 \\
\hline (Female) & - & - & - & & - & - \\
\hline $15-44$ & 0.003 & 0.977 & 1.003 & 0.086 & 0.512 & 1.089 \\
\hline 45-64 & -0.102 & 0.308 & 0.903 & 0.057 & 0.681 & 1.058 \\
\hline$(65+)$ & & - & & & - & - \\
\hline Savannah Zone & -0.432 & 0.000 & 0.649 & 0.296 & 0.097 & 1.344 \\
\hline Forest Zone & 0.084 & 0.237 & 1.088 & 0.282 & 0.002 & 1.325 \\
\hline (Coastal Zone) & - & - & - & - & - & \\
\hline Not married & 0.426 & 0.000 & 1.531 & 0.311 & 0.001 & 1.365 \\
\hline (Married) & - & - & - & - & - & \\
\hline No personal health & 0.118 & 0.351 & 1.125 & 0.132 & 0.193 & 1.141 \\
\hline (Personal health) & - & - & - & - & - & \\
\hline Lower Class & -0.095 & 0.420 & 0.909 & 0.079 & 0.557 & 1.083 \\
\hline Middle Class & -0.168 & 0.148 & 0.845 & 0.031 & 0.817 & 1.032 \\
\hline (Upper Class) & - & - & - & - & - & \\
\hline Constant & -2.034 & 0.000 & 0.131 & -2.218 & 0.000 & 0.109 \\
\hline & Chi-square & 103.614 & & & 68.819 & \\
\hline & df & 10 & & & 10 & \\
\hline & Significance & 0.000 & & & 0.000 & \\
\hline
\end{tabular}

Source: Core Welfare Indicators Questionnaire (CWIQ), 1997. 


\section{Interaction Effects}

The outcome of the interaction analysis indicate that for household heads of lower class status (equation i) in the rural area, the odds of having malaria are about three times as great for the unmarried household head as they are for the married household head. For the rural middle class (equation ii) on the other hand, the odds of having malaria are about 2.21 times as great for the unmarried household head as they are for the married household head. In the urban area, the odds are about twice as large for the unmarried as they are for the married in the lower class (equation iii). For the middle class, the odds are one-and-a-half times as great for the unmarried household head as they are for the married household head (equation iv).

With respect to personal hygiene, on the other hand, it would be observed that for household heads of rural lower class (equation v) and middle class (equation vi) statuses, the odds of having malaria are about two times and a little over oneand-a-half times respectively as large for those who do not observe personal hygiene as they are for those who do. In the urban area on the other hand, the odds of having malaria for household heads of lower class (equation vii) who do not observe personal hygiene are about one-and-a-half times more than they are for those who do, while for household heads of middle class (equation viii) position, the odds are 1.16 times less for those who do not observe personal hygiene as they are for those who do.

\section{Discussion and Conclusions}

The analysis failed to support a direct association between social class and malaria as predicted. In other words, the study found that social class has no direct association with malaria prevalence among household heads in Ghana. This outcome should be treated with caution since it may have been influenced by the way the predictor variable was set up in this study. Although the study also revealed differences in malaria by urban and rural locations, the differentials were statistically insignificant.

The underlying cause of the findings in Table 6 may be traced to a number of factors, the first of which is the composite index used in stratifying the population. It may be that some of the indicators included, either singularly or jointly did not capture sufficiently the characteristics of the intended social group. Second, it is also possible that the method used in delineating the sample was not good enough to provide a near approximation of the membership of each social group in Ghana. It is worthy to note that even after allowing for the measurement problems inherent in the indicators, and the unexpected 
directionality in some of the results, the internal and external validity of the index constructed were established. In addition, further statistical tests all indicated a very high degree of consistency between the index on the one hand, and the other variables. In light of above, not much could be attributed to data or coding problems.

In any case, as the problem would seem to be limited to the rural area, one could speculate that there were differences in response for rural and urban respondents as a result of different perceptions of the symptoms of malaria versus other diseases, and differing access to healthcare and medical diagnoses of the condition, if present. A related issue would then be whether a set of different indicators should have been used or different cut-off points should have been applied to the rural and urban areas in delineating the social groups. One cannot avoid noting that both suggestions evoke methodological issues concerning validity and bias which in turn, would lead to problems of comparability of findings. And specifically with respect to the present study, it calls into serious question the validity of comparisons across different

subgroups, that is, rural and urban. It may be that a closer examination of the social class index and the role played by education and income in social stratification may provide some clue.

In constructing the index, it was observed that household heads belonging to the upper class in the rural area did not score as high on the education factor as their urban counterparts. This, in effect, means that their membership of the upper class is due largely to higher scores on factors that were disproportionately skewed in favour of rural household heads (e.g., dwelling ownership and heads of cattle). It is obvious that these two factors translate into income which invariably provides household heads of upper class status with the means to seek medical attention when they are sick compared to other disadvantaged social groups who may not be in a position to afford the cost of healthcare and therefore resort to self-treatment. It is also possible that even if healthcare services are not available in the rural area, a household head belonging to the upper class could obtain such services from a nearby urban centre but still reported as a rural resident in the survey.

Coupled with above is the fact that the social status of household heads belonging to the upper class in the rural area also increases their awareness of malaria even if they are not the average educated person as would be found in the urban area. If it turns out that the rural upper class household head is also the educated type, their level of awareness is enhanced even the more. So whichever way one looks at it, income and increased awareness result in higher reportage among household heads belonging to the upper class in the rural area than it would occur in the other social groups with relatively less income or education. 
The same cannot be said of the urban area where healthcare services are readily available and relatively cheaper and hence can be accessed by all class of household heads. Hence the finding in the urban area can be seen as demonstrating what would normally be expected of class effect more clearly than in the case of the rural area.

Interestingly, these results are in conformity with the distributions obtained in the cross-classification analysis. This means the outcome is consistent with the data, even though it is not statistically significant. And the non-significance is indication that social class does not influence malaria prevalence among household heads in either rural or urban Ghana, a fact consistent with other studies that have sought to investigate the effect of socioeconomic or social class factors on the prevalence of malaria in other countries (Luckner et al., 1998 and Koram et al., 1995).

One significant outcome overall, is that marital status mediates the relationship between social class and malaria prevalence in both rural and urban areas. Even where marital status interacts with social class, the dominance of the former on the outcome is strikingly obvious. Future research should investigate the possible ways in which being married as opposed to being single or unmarried relates to differential exposure to malaria.

One potential avenue for study is the selection hypothesis, which says that married people are selected for better health and that this translates into lower risk, somehow, of malaria. Another hypothesis argues that marriage protects one against disease through marriage's role as a form of social control on risky lifestyles and behaviours (Trovato and Lauris, 1989; Lillard and Waite, 1995). It seems doubtful, however, that these explanations are of major relevance in the case of malaria since transmission of the disease is highly dependent on exposure to the mosquito, and virtually all - married or not married - are bound to be more or less equally exposed to this agent in the context of Ghana. So it is not clear how marital status per se plays a role in malaria transmission as compared with the "protective" role marriage plays in Western societies via the protection hypothesis argument. Nevertheless, this seems important enough to warrant further attention in future research.

As with all studies involving secondary data, some weaknesses cannot pass without comment. As mentioned elsewhere, the measurement of the dependent variable, malaria represents a serious problem since it is not confirmed by laboratory procedures. Self-reporting of any event is very subjective and represents a major limitation of any study in which such a variable is used. In most developing countries with low levels of education as obtained in Ghana, the presence or absence of malaria is more culturally determined and may be at 
variance with a clinical diagnosis. Given that malaria is the most common disease, symptoms of other illnesses, especially fever may be reported as malaria resulting in over-reporting in some cases and under-reporting in the case of other diseases.

The second problem is a methodological issue concerning the use of multiple indicators and the fact that social class is not significant in this study. As mentioned elsewhere, it is possible that the indicators used in the construction of the index did not adequately capture the characteristics of social class in Ghana, or the method used in delineating the social groups was not rigid enough to provide a close approximation of the membership of each social group. It could also be that if a set of different indicators were used, or different cut-off points were applied to the rural and urban sub-samples, we may not have encountered such a problem. This raises the issue as to whether the indicators selected for the social class index of a particular geographical area could be similarly applied to another geographical area, considering that each component is capable of exerting different effects. But such a procedure if applied would lead to problems of comparability. In any case, tests conducted prior to the analysis indicated a very high degree of consistency between the index constructed and the other variables and as a result, the problem could not be attributed to data or coding problems.

Lastly, in generalizing the outcome of this study to the entire population, one needs to exercise some caution in view of the fact that if potential observations from some population of interest are excluded from a sample on a non-random basis, one risks introducing into the analysis sample selection bias (Berk, 1983). In Ghanaian society, all household heads would normally be adults and so the sample used in this study cannot be considered representative of the Ghanaian population, more so when children under five who are known to be the population most at risk of malaria are excluded. Even for the adult group, identifying pregnant women among them would have enhanced our understanding of the problem since they are the adult group most at risk. As well, bed net ownership is also a good indicator of wealth and could also have contributed to a much better understanding of the problem if the information were available given the demonstrated effectiveness of TINs. It is also important to point out that the fact that social class is not a key factor in the transmission of malaria in Ghana as the results obtained in this study suggest does not mean the same results would be obtained in other sub-Saharan African countries. The above problems notwithstanding, this study represents a good effort at exploring the social and economic aspects of malaria prevalence in a developing country that is so much lacking in the literature. 


\section{Acknowledgement:}

The authors express their gratitude to the Ghana Statistical Service who provided the data set for the study; and the anonymous reviewers for their insightful comments and criticisms that led to substantial improvements to the paper.

\section{References:}

Afari, Edwin A. 1994. "In vivo seasonal assessment of Plasmodium falciparum sensitivity to chloroquine in two different malaria endemic communities in Southern Ghana," African Journal of Health Sciences, 1: 112-115.

Ahmed, Kofi. 1989. "Epidemiology of Malaria in Ghana," Ghana Medical Journal, 23: 190-196.

Aikins, M. K., Pickering, H., Greenwood, B. M. 1994. “Attitudes to Malaria, Traditional Practices and Bednets (mosquito nets) as Vector Control Measures: A Comparative study in five West African Countries,' Journal of Tropical Medicine and Hygiene, 97: 81-86.

Akazili, J. 2003. Costs to Households of Seeking Malaria Care in the KassenaNankana District of Northern Ghana", in Third Multilateral Initiative on Malaria (MIM) Pan-African Conference on Malaria, Arusha, Tanzania, 17-22 November, 2002. Bethesda, MD, Multilateral Initiative on Malaria: abstract 473 .

Alnwick, David. 2000. "Roll Back Malaria - what are the prospects?" Bulletin of the World Health Organization, 78(12).

Bawden, Monte P., Douglas D. Slaten and John D. Malone. 1995. "Falciparum malaria in a displaced Haitian population," Transactions of the Royal Society of Tropical Medicine and Hygiene, 89: 600-603.

Berk, Richard A. 1993. "An Introduction to Sample Selection Bias in Sociological Data,” American Sociological Review, 48: 386-398.

Brabin, L and B. J. Brabin. 1992. "Parasitic infections in women and their consequences," Advances in Parasitology, 31: 1-81. 
Kwami Boadu and Frank Trovato

Brown, P. J. 1997. "Culture and the Global Resurgence of Malaria," in Inhorn, M. C.,Brown, P. J., (eds). The Anthropology of Infectious Disease: International Health Perspectives, $2^{\text {nd }}$ edition. Amsterdam, Gordon and Breach Science Publishers, 119-141.

Carr-Hill, R. 1989. "The Inequalities in Health Debate: a critical review of the issues," Journal of Social Politics, 16: 509-542.

Centers, R. 1950. The Psychology of Social Classes, Princeton: Princeton University Press.

Chen, M. M and D. P. Wagner. 1978. "Gains in Mortality from Biomedical Research 1930-1975: An Initial Assessment," Social Science and Medicine, 49(4): 509-38.

Dohrenwend, B.P. and B. S. Dohrenwend. 1969. "Social Status and Psychological Disorder: A Causal Inquiry," New York: John Wiley and Sons.

Ejov, M. N., T. Tun, S. Aung, S. Lwin and K. Sein. 1999. "Hospital-based study of severe malaria and associated deaths in Myanmar," Bulletin of the World Health Organization, 77(4): 310-314.

Feinstein, J. 1993. "The Relationship Between Socioeconomic Status and Health: A Review of the Literature," Milbank Quarterly, 71: 279-322.

Giha, Haider A., Susanne Rosthoj, Daniel Dodoo, Lars Hvid, Gwira, M. H, Satti, Thomas Scheike, David E. Arnot and Thor G. Theander. 2000. "The Epidemiology of febrile malaria epdisodes in an area of unstable and seasonal transmission," Transactions of the Royal Society Tropical Medicine and Hygiene, 94: 645-651.

Haan, M., G. A. Kaplan and T. Camacho. 1987. "Poverty and Health: Perspective Evidence from the Alameda County Study," American Journal of Epidemiology, 125: 989-998.

Heggenhougen, H. K., V. Hackethal, P. Vivek. 2003. "The behavioural and Social Aspects of Malaria and its Control," World Health Organization.

Hollingshead, A. B. and F. C. Redlich. 1958. Social Class and Mental Illness, New York: Wiley and Sons. 
Inhorn, M. C. and P. J. Brown. 1990. "The Anthropology of Infectious Disease," Annual Review of Anthropology, 19: 89-117.

Jamison, Dean T., W. Henry Mosley, Anthony R. Measham and Jose Luis Bobadilla. 1993. "Disease Control Priorities in Developing Countries," Oxford University Press.

Jones, C., T. Laviest and M. Lillie-Blanton. 1991. "Race in the epidemiologic literature: An examination of the American Journal of Epidemiology 1921-1990," American Journal of Epidemiology, 134: 1079-1084.

Kim, Jae-On and C. W. Mueller. 1978. Factor Analysis: Statistical Methods and Practical Issues. Sage University Paper Series On Quantitative Applications in the Social Sciences. Series No. 07-014. Beverly Hills and London: Sage Publications.

King, G. and D. Williams. 1992. "Race and Health: A Multidimensional Approach to African-American Health", Paper presented at the Society and Health Conference, Oct. 12-15, Boston, MA.

Koram, K. A., S. Bennett, J. H. Adiamah. 1995. "Socioeconomic determinants are not major risk factors for severe malaria in Gambian children," Transactions of the Royal Society of Tropical Medicine and Hygiene, 89: 151-154.

Kuate, D. B. 1997. "Effects of Socioeconomic Advantage and Women's Status on Women's Health in Cameroon," Social Science and Medicine, 44(7): 1023-1042.

Laserson, Kayla F., David Wypij, Izaskun Petralanda, Andrew Speilman and James H. Maguire. 1999. "Differential Perpetuation of Malaria species among Amazonian Yanomami Amerindians," American Journal of Tropical Medicine and Hygiene, 60 (5): 767-773.

Lienhardt, C., R. Ghebray, E. Candolfi, T. Kien and G. Hedlin. 1990. "Malaria in refugee camps in eastern Sudan: a sero-epidemiological approach," Annals of Tropical Medicine and Parasitology, 84: 215-222.

Lillard, Lee A. and Linda J. Waite. 1995. "'Til Death Do Us Part': Marital Disruption and Mortality," The American Journal of Sociology, 100(5): 1131-1156. 
Lindsay, S. W. and W. J. M. Martens. 1998. Malaria in the African Highlands: past, present and future. Bulletin of the World Health Organization, 76: $33-45$.

Luckner, D., B. Bell, B. Greve, L. G. Lehman, R. J. Schmidt-Ott, P. Matousek, K. Herbich, D. Schmid, R. Mba and P. G. Kremsner. 1998. "No influence of socioeconomic factors on severe malarial anaemia, hyperparasitemia or reinfection," Transactions of the Royal Society of Tropical Medicine and Hygiene, 92: 478-481.

Marmot, M. G. and T. Theorell. 1988. "Social Class and Cardiovascular Disease: The Contribution of Work," International Journal of Health Services, 18: 659-674.

Marmot, M. G., G. Davey Smith, S. Stansfeld, C. Patel, F. North, J. Head, I. White, E. J. Brunner and A. Feeney. 1991. "Health Inequalities among British civil servants: the Whitehall II Study," Lancet, 337: 1387-1393.

Marmot, M. G., M. Kogevinas, and M. A. Elston.. 1987. "Social/Economic Status and Disease," Annual Review of Public Health, 8: 111-135.

Mayer, K. B. 1955. Class and Society. New York: Doubleday and Co.

Mwageni, E. 2002. "Household Wealth Ranking and Risks of Malaria Mortality in Rural Tanzania", in Third Multilateral Initiative on Malaria (MIM) Pan-African Conference on Malaria, Arusha, Tanzania, 17-22 November, 2002. Bethesda, MD, Multilateral Initiative on Malaria: abstract 12.

Robert, V and Carnevale, P. 1991. "Influence of Deltamethrin Treatment of Beds on Malaria Transmission in the Kou valley, Burkina Faso," Bulletin of the World Health Organization, 69(6): 735-740.

Roll Back Malaria. RBM. 2004. Malaria in Pregnancy. From RBM website: http://www.rbm.who.int/cmc. Accessed January 25, 2005.

Roll Back Malaria [RBM/WHO]. 2000. RBM Advocacy Guide, Geneva, World Health Organization.

Roll Back Malaria (RBM) National Secretariat. 2001. Report on the Zambia Roll Back Malaria Baseline Study Undertaken in 10 Sentinel Districts, July-August 2001. 
Snow, R. W., R. Ikoku, J. Omumbo and J. Ouma. 1999. “The Epidemiology, Politics and Control of Malaria Epidemics in Kenya:1900-1998”, report prepared for RBM Resource Network on Epidemics, WHO, July, 1999.

Steketee, R. W., Benard L., Nahlen M., Parise E., and Mehendez C. 2001. "The Burden of Malaria in Pregnancy in Malaria-Endemic Areas," American Journal of Tropical Medicine and Hygiene, 64(1, 2 S): 28-35.

Trovato, Frank and Gloria Lauris. 1989. "Marital Status and Mortality in Canada: 1951-1981," Journal of Marriage and the Family, 51: 907-922.

UNICEF, WHO. 2003. "Antenatal Care in Developing Countries: Promises, Achievements, and Missed Opportunities. An Analysis of Levels, Trends and Differentials, 1990-2001."

Vagero, D. 1991. "Inequality in Health - Some Theoretical and Empirical Problems," Social Science and Medicine, 32: 367-371.

Vlassof, C and Bonilla, E. 1994. "Gender-related Differences in the Impact of Tropical Disease on Women: What we Know," Journal of Biosocial Science, 26(1): 37-53.

Wilkinson, Richard G. 1996. Unhealthy Societies: The Afflictions of Inequality. London: Routlidge.

Williams, D. R. 1990. "Socioeconomic Differentials in Health: A Review and Redirection," Social Psychology Quarterly, 53: 81-99.

World Health Organization [WHO]. 2003. Strategic Framework for Malaria Control During Pregnancy in the WHO African Region. Geneva.

Wrong, D. H. (1980), Class Fertility Trends in Western Nations. New York: Arno Press.

Ziba, C., L. Chitsulo and R. W. Steketee. 1994. "Use of Malaria Prevention Measures in Malawian Households," Tropical Medicine and Parasitology, 45: 70-73. 